To be presented at the $49^{\text {th }}$ ECTC in San Diego, CA 1-4 June, 1999

\title{
Calculation and Validation of Thermomechanical Stresses in Flip Chip BGA Using the ATC4.2 Test Vehicle
}

\author{
David W. Peterson, Steven N. Burchett, James N. Sweet and Robert T. Mitchell \\ Sandia National Laboratories \\ PO Box 5800 \\ Albuquerque, NM 87185-1082 \\ Luu Nguyen \\ National Semiconductor \\ PO Box 58090 \\ Santa Clara, CA 95052
}

\begin{abstract}
We report the first in situ measurements of thermomechanical stresses in a $1000 \mathrm{I} / \mathrm{O} 250 \mu \mathrm{m}$ pitch piezoresistive flip chip test chip assembled to a 755 IO 1.0 $\mathrm{mm}$ pitch $35 \mathrm{~mm}$ Ball Grid Array (BGA). The BGA substrates employed "build-up" dielectric layers containing micro-vias over conventional fiberglass laminate cores. Experimental data, which include in situ stress and die bending measurements, were correlated to closed form and Finite Element Method (FEM) calculations. Cracking and delamination were observed in some of the experimental groups undergoing temperature cycling. Through use of bounding conditions in the FEM simulations, these failures were associated with debonding of the underfill fillet from the die edge that caused stresses to shift to weaker areas of the package.
\end{abstract}

\section{Introduction}

This work focuses on thermomechanical stresses present in a flip chip test vehicle that was designed to meet the 1997 NTRS flip chip substrate requirement in the cost-performance category. This requirement calls for a $12 \mathrm{~mm}$ die with $900-$ $1000 \mathrm{~V} / \mathrm{O}$ on $250 \mu \mathrm{m}$ pitch on a $35 \mathrm{~mm}$ Ball Grid Array (BGA) substrate with $600-700 \mathrm{I} / \mathrm{O}$ on $1.0 \mathrm{~mm}$ pitch. The actual test vehicle used the $11.56 \mathrm{~mm} \mathrm{ATCO4}$ piezoresistor test chip repatterned to a 1004 bump area array (making it an ATC4.2) assembled to a $35 \mathrm{~mm}$ BGA substrate with $755 \mathrm{I} / \mathrm{O}$. The experimental approach follows that of earlier work with the ATC4.1 test vehicle which examined thermomechanical stresses in flip chip on board (FCOB) [1]. Independent measurements of die curvature and in situ stress were used to validate and refine analytical and FEM calculations of deflection and stress. The latter were also mutually independent in the sense that analytical results were based on direct measurements of CTE and bending modulus on coupons and FEM calculations were based on data sheet properties of the constitutive elements of each assembly.

\section{Experimental}

Test Vehicle

The ATC4.2 Flip Chip Test Chip is a redistributed area array version of the ATC04 Assembly Test Chip that is 11.56 $\mathrm{mm}$ on an edge and contains 100 addressable stress sensing cells, ring oscillators, and heaters described in detail elsewhere [2]. The area array consists of 1004 eutectic solder bumps applied by two suppliers (Bmpl and Bmp2) with slightly different bump technologies, although both used $\mathrm{BCB}$ (benzocyclobutene) for dielectric and $\mathrm{Cu}$ for interconnect layers. Due to a design incompatibility only one of two bump suppliers (Bmp2) furnished die capable of providing stress measurements.

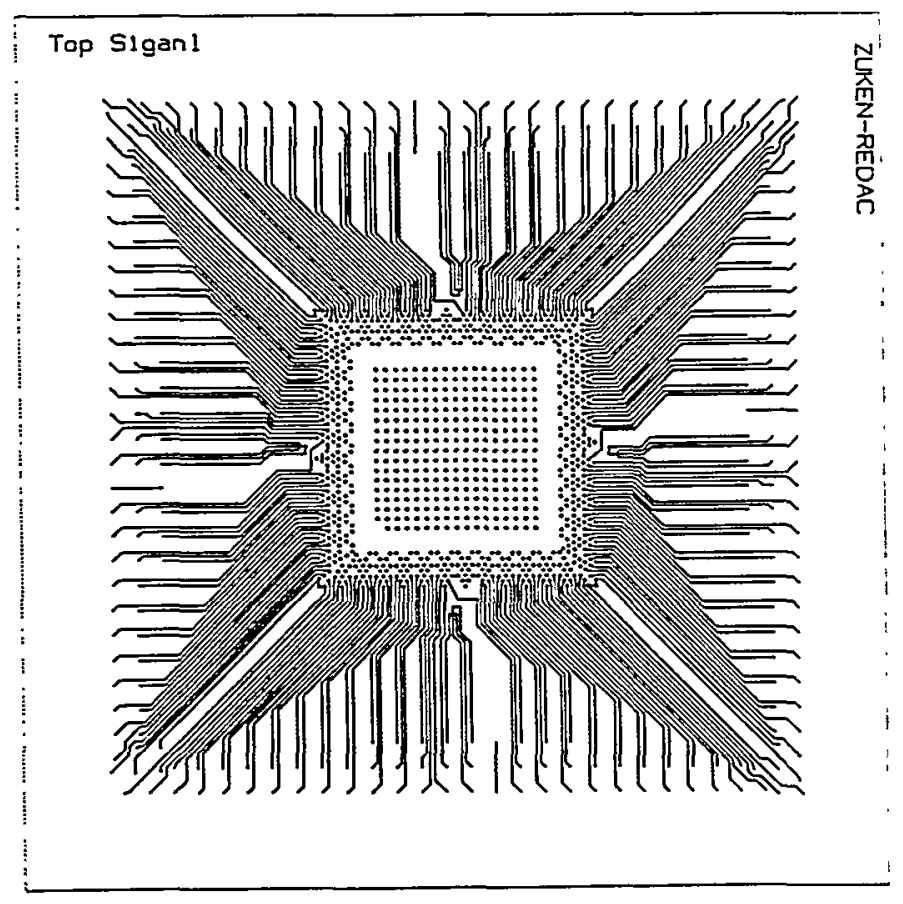

Fig. 1. Top layer die pad layout and outer row escape routing of the Zuken-Redac layout of the $35 \mathrm{~mm}$ ATC4.2 BGA substrate. Flip chip pads for the $1004 \mathrm{~V} / \mathrm{O} 250 \mu \mathrm{m}$ pitch die are in the center. The BGA array on the bottom contains 755 solder balls on $1.0 \mathrm{~mm}$ pitch.

\footnotetext{
'Sandia is a multiprogram laboratory operated by Sandia Corporation, a Lockheed Martin Company, for the United States Department of Energy under Contract DE-AC04-94AL85000.
} 


\section{DISCLAIMER}

This report was prepared as an account of work sponsored by an agency of the United States Government. Neither the United States Government nor any agency thereof, nor any of their employees, make any warranty, express or implied, or assumes any legal liability or responsibility for the accuracy, completeness, or usefulness of any information, apparatus, product, or process disclosed, or represents that its use would not infringe privately owned rights. Reference herein to any specific commercial product, process, or service by trade name, trademark, manufacturer, or otherwise does not necessarily constitute or imply its endorsement, recommendation, or favoring by the United States Government or any agency thereof. The views and opinions of authors expressed herein do not necessarily state or reflect those of the United States Government or any agency thereof. 


\section{DISCLAIMER}

Portions of this document may be illegible in electronic image products. Images are produced from the best available original document. 
The BGA substrate design incorporates three perimeter rows of off-grid die pads on $250 \mu \mathrm{m}$ pitch using a "clamshell" technique first described by Gasparini and Bhattacharyya máximizing escape routing of an area array with a minimum number of layers [3]. The actual layout was furnished by Zuken-Redac as part of a voluntary contribution to this work. The first layer die pad layout and escape routing for this design is shown in Fig. 1.

The Zuken-Redac design was used by two suppliers of $\mathrm{PC}$ boards to fabricate BGA substrates, SubA and SubB, shown in cross-section in Figs. 2 and 3. Both use fiberglass reinforced cores and epoxy build-up $(B / U)$ layers containing microvias for layer-to-layer interconnection. SubA has a thinner core and uses three $B / U$ layers and SubB has a thicker core with two $B / U$ layers.

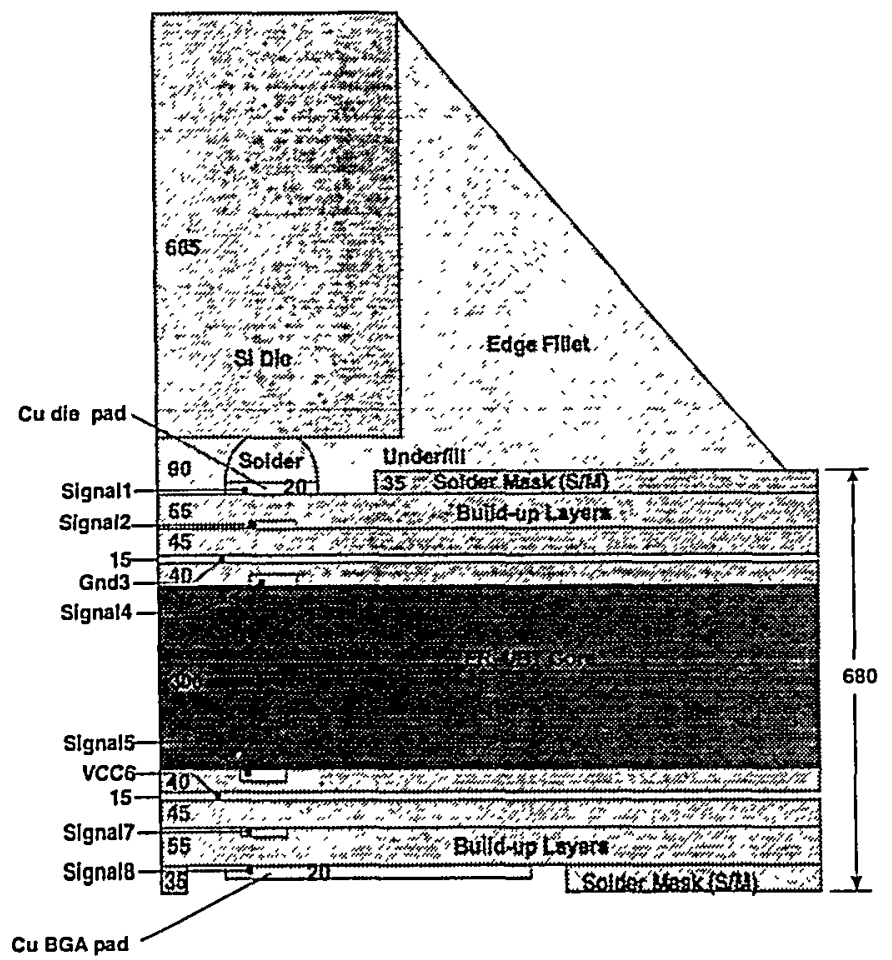

Fig. 2. Cross-section of SubA with thickness dimensions in microns.

TABLE I

Material Properties used in FEM calculations

\begin{tabular}{lccccc}
\hline & $\begin{array}{c}\mathrm{E} \\
(\mathrm{GPa})\end{array}$ & $\begin{array}{c}\mathrm{Tg} \\
\left({ }^{\circ} \mathrm{C}\right)\end{array}$ & $\begin{array}{c}\alpha 1 \\
\left(10^{-6} /{ }^{\circ} \mathrm{C}\right)\end{array}$ & $\begin{array}{c}\alpha 2 \\
\left(10^{-6} /{ }^{\circ} \mathrm{C}\right)\end{array}$ & $v$ \\
\hline Silicon & 120 & $\mathrm{n} / \mathrm{a}$ & 2.6 & $\mathrm{n} / \mathrm{a}$ & 0.34 \\
Copper & 107.6 & $\mathrm{n} / \mathrm{a}$ & 16.1 & $\mathrm{n} / \mathrm{a}$ & 0.334 \\
UF1 & 5.8 & 145 & 40 & unk & 0.3 \\
UF2 & 8.5 & 140 & 26 & 87 & 0.3 \\
UF3 & 11 & 125 & 31 & 89 & 0.3 \\
Solder Mask A & 0.25 & 105 & 60 & 160 & 0.25 \\
Solder Mask B & 5.8 & 132 & 49 & 120 & 0.25 \\
Build-upA & 5.8 & 190 & 70 & $\mathrm{n} / \mathrm{a}$ & 0.3 \\
Build-upB & 3.1 & 119 & 78 & 176 & 0.3 \\
CoreA & 2.45 & 190 & 14 & $\mathrm{n} / \mathrm{a}$ & 0.2 \\
CoreB & 16.4 & 170 & 14.7 & unk & 0.2 \\
\hline
\end{tabular}

Table I contains the test vehicle material properties used in the FEM analysis. The properties for $\mathrm{Si}$ are averages of the minimum and maximum anisotropic values in the [100] and [110] directions. Underfill and substrate properties were obtained from the respective vendors. Analytical calculations used properties contained in Table II that were derived from direct measurements of CTE and bending modulus on bare coupons.

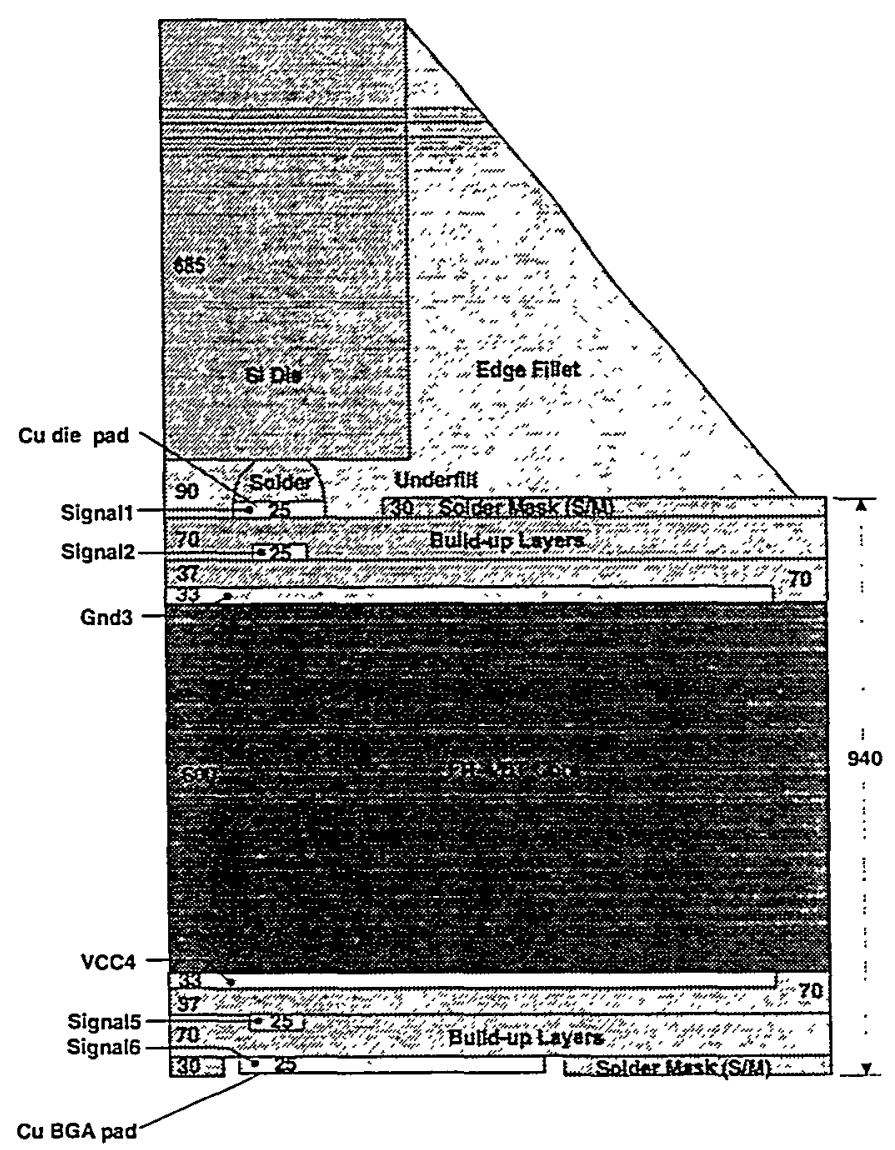

Fig. 3. Cross-section of SubB with thickness dimensions in microns.

TABLE II

Laminate properties used in analytical calculations

\begin{tabular}{lcccc}
\hline & $\begin{array}{c}\mathrm{E} \\
(\mathrm{GPa})\end{array}$ & $\begin{array}{c}\alpha \\
\left(10^{-6} /{ }^{\circ} \mathrm{C}\right)\end{array}$ & $v$ & $\begin{array}{c}\text { Thickness } \\
(\mu \mathrm{m})\end{array}$ \\
\hline SubA & 8.8 & 21.8 & 0.25 & 680 \\
SubB & 10.9 & 19.3 & 0.25 & 940 \\
\hline
\end{tabular}

\section{Experimental Procedure}

ATC4.2 die solder bumped by two bump suppliers, Bmpl and Bmp2, were flip chip assembled to SubA and SubB substrates using three underfills, UF1, UF2, and UF3. Celestica performed flip chip assembly including attachment and coining of eutectic solder balls on the BGA side. Bmpl die were assembled to both substrate splits but $B \mathrm{mp} 2$ die were only assembled to SubA splits. This resulted in a total of 9 experimental legs (see Table III). Since Bmp2 die were assembled only to SubA substrates, in situ stress data were only available for parts in this leg. Assemblies were classitied 
as Level 3 moisture sensitive at National Semiconductor using Test Method A1 12-A of EIA/JEDEC Standard 22. All parts in the, 9 experimental legs underwent Level 3 moisture preconditioning and temperature cycling (T/C) from -45 to $+125{ }^{\circ} \mathrm{C}$. Electrical tests and C-mode Scanning Acoustic Microscopy (C-SAM) inspection were performed at 0,100, $200,300,500$ and $1500 \mathrm{~T} / \mathrm{C}$ intervals, and are continuing to failure at publication. Electrical tests included 4-point resistance measurements of corner solder balls, microvias and van der Pauw sheet resistance structures, daisy chain continuity and piezoresistor measurements. C-SAM images of the underfill interface were used to detect and monitor failures in the die-to-substrate interface.

TABLE III

Splits in the experimental matrix

\begin{tabular}{lccc}
\hline Split & $\begin{array}{c}\text { Solder bump } \\
\text { supplier }\end{array}$ & $\begin{array}{c}\text { Substrate } \\
\text { supplier }\end{array}$ & $\begin{array}{c}\text { Underfill } \\
\text { supplier }\end{array}$ \\
\hline 1 & Bmp1 & SubA & UF1 \\
2 & Bmp1 & SubA & UF2 \\
3 & Bmp1 & SubA & UF3 \\
4 & Bmp1 & SubB & UF1 \\
5 & Bmp1 & SubB & UF2 \\
6 & Bmp1 & SubB & UF3 \\
7 & Bmp2 & SubA & UF1 \\
8 & Bmp2 & SubA & UF2 \\
9 & Bmp2 & SubA & UF3 \\
\hline
\end{tabular}

\section{Deflection Measurements}

Die curvature at room temperature were measured along the $x$-axis and $y$-axis of the die backside using a Mahr S8P profilometer with a Focodyn laser stylus. Parts were aligned in a machined fixture to ensure repeatable measurements along the die centerline in both directions. Data were collected along a $10 \mathrm{~mm}$ path straddling the geometric die center and vertical deflections were calculated for a $7.14 \mathrm{~mm}$ segment of this path. The average of the $x$ and $y$ deflection measurements were calculated for each part. Table IV contains measurements taken at the $200 \mathrm{~T} / \mathrm{C}$ inspection interval.

TABLE IV

Measurements of die curvature over a $7.14 \mathrm{~mm}$ arc

\begin{tabular}{lcc}
\hline $\begin{array}{l}\text { Experimental Split } \\
\text { (Nr. parts) }\end{array}$ & $\begin{array}{c}\text { Average } \\
\text { Deflection } \\
(\mu \mathrm{m})\end{array}$ & $\begin{array}{c}\text { Standard } \\
\text { Deviation } \\
(\mu \mathrm{m})\end{array}$ \\
\hline Bmp1/SubA/UF1 (9) & 9.1 & 0.2 \\
Bmp1/SubA/UF2 (9) & 8.5 & 0.1 \\
Bmp1/SubA/UF3 (9) & 9.0 & 0.1 \\
Bmp1/SubB/UF1 (9) & 8.0 & 0.2 \\
Bmp1/SubB/UF2 (9) & 8.0 & 0.1 \\
Bmp1/SubB/UF3 (9) & 8.1 & 0.1 \\
Bmp2/SubA/UF1 (4) & 8.7 & 0.1 \\
Bmp2/SubA/UF2 (4) & 8.4 & 0.2 \\
Bmp2/SubA/UF3 (4) & 8.7 & 0.2 \\
\hline
\end{tabular}

\section{Experimental Stress Measurements}

The second independent measure of die stress was based on piezoresistor data from 100 rosettes distributed across each
ATC4.2 die. Piezoresistors formed on CMOS [100] are sensitive to in-plane compressive and shear components of the stress tensor but cannot detect out-of-plane components that are generally of the most interest in terms of packaging reliability. However, the in-plane data can be used to validate in-plane results from analytical and FEM calculations and, by inference, out-of-plane predictions. These data will be presented in the Discussion section where we compare experimental, analytical and FEM results.

\section{D Stress Analysis}

Radius of curvature and the distribution of in and out-ofplane stresses were estimated using the tri-material form of Suhir's model described in [4] with improvements for out-ofplane shear and peel stress calculation in [5]. Although this model does not take into account the effect of the flip chip edge fillet, it provides a good prediction of stress maximums and die deflection. Die and underfill properties were taken from Table I and substrate properties from Table II. Radius of curvature data were converted to die deflections over a 7.14 $\mathrm{mm}$ arc so that they could be more easily compared to measured deflections. These results are contained in Table V. Analytical and FEM calculations are very dependent on estimations of the stress-free temperature. For this work, it was assumed to be the $\mathrm{Tg}$ of the underfill listed in Table I, so that $\Delta \mathrm{T}=\mathrm{Tg}-25^{\circ} \mathrm{C}$.

TABLE V

Calculations of maximum $\sigma y y, \sigma z z$, and $\tau y z$ and radius of curvature converted to die deflection from Suhir. Maximum $\sigma y y$ is located at die center, maximum $\sigma \approx$ and $\tau y z$ are at die edge.

\begin{tabular}{lcccc}
\hline $\begin{array}{l}\text { Experimental } \\
\text { Split }\end{array}$ & $\begin{array}{c}\sigma y y \max \\
(\mathrm{Mpa})\end{array}$ & $\begin{array}{c}\sigma z z \max \\
(\mathrm{Mpa})\end{array}$ & $\begin{array}{c}\tau y z \max \\
(\mathrm{Mpa})\end{array}$ & $\begin{array}{c}\text { Deflection } \\
(\mu \mathrm{m})\end{array}$ \\
\hline SubA/UF1 & -108 & 7.3 & 17.5 & 9.3 \\
SubA/UF2 & -102 & 6.2 & 16.9 & 8.8 \\
SubA/UF3 & -93 & 4.9 & 16.8 & 8.0 \\
SubB/UF1 & -104 & -0.01 & 15.6 & 8.9 \\
SubB/UF2 & -98 & -0.3 & 15.1 & 8.5 \\
SubB/UF3 & -88 & -.3 & 14.9 & 7.6 \\
\hline
\end{tabular}

\section{D Stress Analysis}

The 3D FEM was applied to a quarter section model of the BGA assembly to predict the stress, strain and deformation response due to the cool down from the underfill cure step. For this analysis we assume the stress-free temperature to be the cure temperature of the underfill $\left(160{ }^{\circ} \mathrm{C}\right)$. The viscoelastic model used for polymer materials take into account the $\mathrm{Tg}$ of the materials in calculating stress. The model specifically accounts for each layer in the substrate and includes the edge fillet but neglects the 251 solder balls in the underfill region. To capture the stress distributions, the model size was greater than 500,000 elements. These simulations were performed using the Sandia quasi-static analysis code JAS3D on six parallel processors of a DEC-8400.

Table VI contains stress maximums for the components $\sigma y y, \sigma z z$, and $\tau y z$ along the centerline half-length of the die surface and die deflections over a $7.14 \mathrm{~mm}$ arc to facilitate 
comparison to curvature measurements. These calculations were done for the three SubB underfill splits and included one for UF2 that neglected the fillet. The latter experienced problems with numerical oscillations in the last few elements approaching the die edge, so the $\sigma z z$ and $\tau y z$ maximums, which occur at tehe edge, are correct in sign but uncertain in magnitude. Recalculation of the no-fillet case along with calculation of the remaining SubA cases are ongoing at the time of printing.

\section{TABLE VI}

FEM calculations of maximum $\sigma y y, \sigma z z$, and $\tau y z$ along the centerline half-length of the die surface and deflection over a $7.14 \mathrm{~mm}$ arc. Maximum $\sigma y y$ is located at die center, maximum $\sigma z z$ and $\tau y z$ are at die edge. (NF stands for no edge fillet.)

\begin{tabular}{lcccc}
\hline $\begin{array}{l}\text { Experimental } \\
\text { Split }\end{array}$ & $\begin{array}{c}\sigma y y \max \\
\text { (Mpa) }\end{array}$ & $\begin{array}{c}\sigma z z \max \\
(\mathrm{Mpa})\end{array}$ & $\begin{array}{c}\tau y z \max \\
(\mathrm{Mpa})\end{array}$ & $\begin{array}{c}\text { Deflection } \\
(\mu \mathrm{m})\end{array}$ \\
\hline SubB/UF1 & -103 & -24 & 24 & 9.3 \\
SubB/UF2 & -101 & -15 & 21 & 9.1 \\
SubB/UF3 & -102 & -28 & 27 & 9.0 \\
SubB/UF2/NF' & -101 & 33 & 17 & 9.1 \\
\hline
\end{tabular}

"Although the sign and general shape of the "no fillet" data appear correct, the maximums are questionable due to numerical oscillations in the last few elements approaching the die edge.

\section{Results/Discussion}

\section{Correlation of Stress Analysis Methods}

There are two relatively simple methods for estimating thermal stress in a CMOS die flip chip attached to an organic substrate: backside deflection and in situ stress measurement. The former is easy but prone to experimental error and misinterpretation., In CMOS technology, the latter can not sense the stress components of most interest. Both are useful when comparing relative differences in stress that are anticipated in material " $A$ " vs. " $B$ " types of experiments, and both can be used to increase confidence in the results of analytical and FEM calculations.

Fig. 4 contains measurements of backside deflection taken after $200 \mathrm{~T} / \mathrm{Cs}$ plotted in a normal probability distribution for each of the substrate and underfill experimental splits. (These data are averaged in Table $\mathrm{IV}$.) It can be deduced from these data that SubB imposes less stress on the die than SubA. This correlates with analytical estimates in Table $\mathrm{V}$ and FEM estimates in Table VI. However, the effect of underfill apparent in the analytical and FEM estimates does not appear in Fig. 4. Small differences in curvature due to underfill appear to be hidden in larger part-to-part statistical variance in curvature (and stress). Given that assumption, the SubA/UF2 data stand out. We associate this with edge delamination in all parts in this group during the course of temperature cycling. Edge delamination will be discussed in more detail below.

2D Analytical methods for calculating thermal stress in a flip chip package often assume, among other things, one infinite dimension in the $x-y$ plane, constant radius of curvature through the $z$-axis, no edge fillet, and are limited to stress distributions along the finite axis in the $x-y$ plane. Stress maximums, die deflection, and stress distributions in the interior region of the uniformly deflected (constant radius of curvature in $x$-y plane) die can be quite accurate if the calculations are based on reliable material property data.

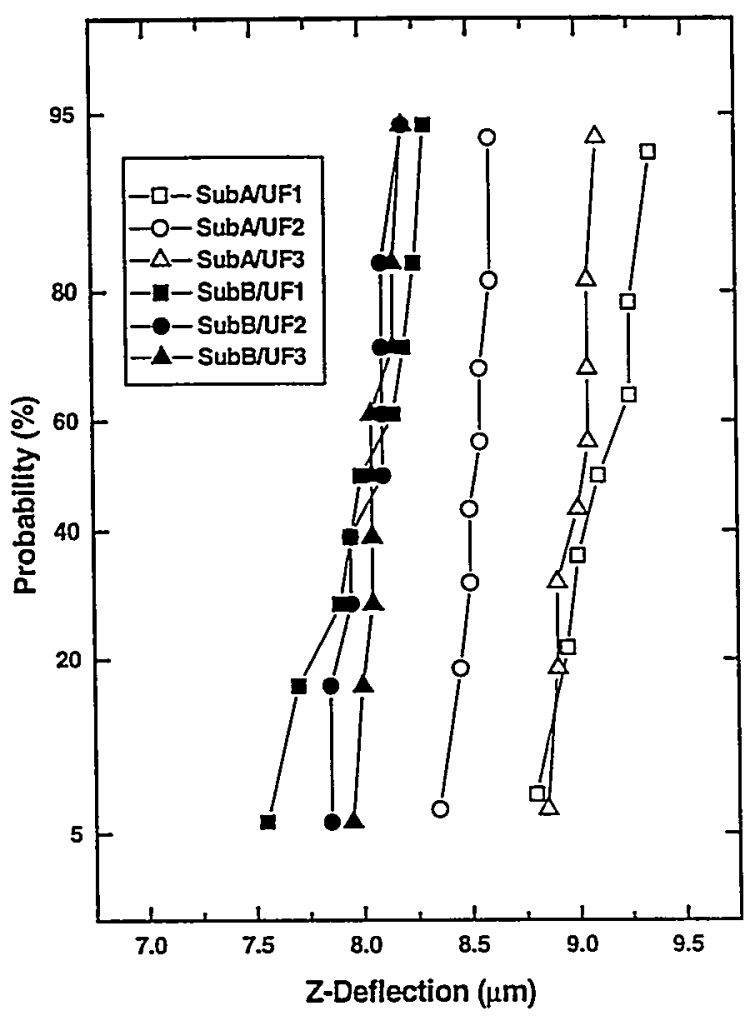

Fig. 4. Normal probability plot of die backside deflection measurements after $200 \mathrm{~T} / \mathrm{C}$ for three underfills and two substrates. Open symbols are data from SubA split and filled symbols are data from SubB. Displacement of the SubA/UF2 distribution is associated with edge delaminations present in all parts of this group.

3D FEM calculations are also highly dependent on reliable property data. Since the FEM specifically models each layer in the substrate, the resulting calculations are based on material properties of uncertain accuracy for each layer from numerous sources. Drastically different elastic moduli for the two core materials and solder masks in Table I, for example, seem questionable, but had to be accepted ultimately when verified by both sources.

FEM calculations in Table VI show a spread across the three SubB underfill splits of $3 \%$ in $\sigma y y$ max and die deflection in contrast to analytical calculations in Table $\mathrm{V}$ that show spreads greater than $17 \%$ for the same predictions. The measured die deflections for the same group varied by less than $2 \%$ suggesting that the FEM is doing better at capturing the effect of underfill. FEM results show greatest sensitivity to underfill in maximum $\sigma z z$, which varies $86 \%$ UF2 $\rightarrow$ UF3.

In order of increasing deflection, both FEM and analytical results rank the underfills: UF3 $\rightarrow U F 2 \rightarrow U F 1$. Analytical maximum oyy and $\tau y z$ follow the same order, but the FEM order is UF2 $\rightarrow$ UF3 $\rightarrow$ UF1 for oyy, and UF2 $\rightarrow U F 1 \rightarrow U F 3$ for $\sigma z z$, and $\tau y z$. Interestingly, both in situ data based on a small split of Bmp2/SubA parts and the underfill "stress intensity 
factor" ranking of $(E) \times(\Delta T) \times(C T E)$ show the order UF2 $\rightarrow$ UF $1 \rightarrow$ UF3 (although it's for $\sigma y y$ in the in situ case).

In-plane compressive stress along the $y$-axis of the die surface centerline is measurable with CMOS piezoresistors and can be estimated with analytical methods, making it a suitable quantity for comparison of stress analysis methods. Fig. 5 contains a plot of $\sigma y y$ along the normalized half-length and includes typical ATC4.2 measurement data of SubA/UF2 parts starting at baseline and continuing through the first 200 T/Cs $\left(-45\right.$ to $\left.+125^{\circ} \mathrm{C}\right)$. These data are overlaid with curves representing the analytical and FEM calculations for SubB/UF2. (SubA FEM calculations were not available at time of publication.) The Suhir stress diminishes to zero at the edge in accordance with classical bending theory but the FEM curve stops short due to the edge fillet. The two calculations match within $3 \%$ in the die center region of constant stress for UF1 and UF2, but is $16 \%$ different for UF3. This is likely due to the unusually low $\mathrm{Tg}$ and thus $\Delta \mathrm{T}$ used for the analytical calculation. FEM used the same $\mathrm{Tg}$ but included the effects of $\alpha 2$ between cure temperature and $\mathrm{Tg}$.

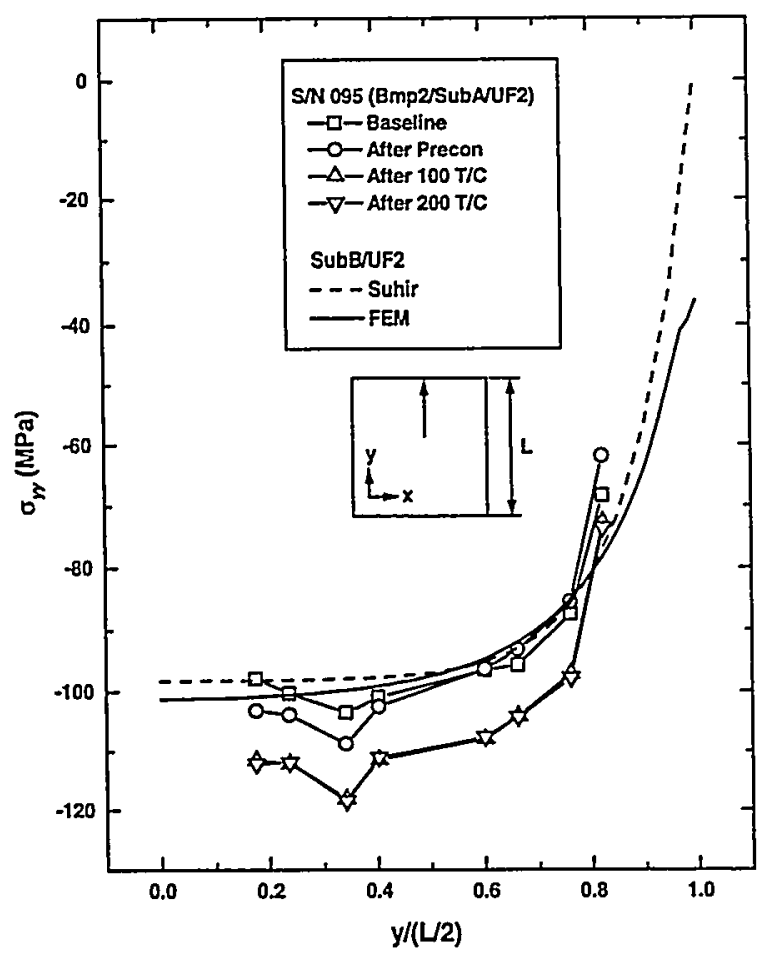

Fig. 5. Plot of $\sigma y y$ distribution (compressive stress on the $y$-plane in the $y$-direction) along the normalized centerline half-length of the die surface. Symbols denote experimental data for a part in Bmp2/SubA/UF2 split. Dotted line is Suhir calcuiation that neglects edge fillet effects and dashed line is from FEM that includes edge fillet. (The latter two curves are based on SubB as SubA calculations were unavailable.)

The experimental data in Fig. 5 contains two anomalies present in all the in situ measurements. First are kink(s) which are known from previous work [1] to be due to stress gradients surrounding solder balls that are in varying proximities to the piezoresistor rosettes. Second is a trend toward increasing stress that appears to end at some point around the first 100 $T / C s$ for which we offer no explanation at this time.

\section{Thermal Stress Damage}

Three kinds of early damage were observed during the course of temperature cycling: die cracking, edge delamination, and radial fillet cracking. Die cracks start at the die edge under the edge fillet and proceed in the die plane emerging somewhere on the inverted die surface. These cracks are not visible on the outside of the package and can only be detected with C-SAM. Fig. 6 contains a C-SAM image of a typical cracked die. Cracking was only observed in the SubA splits for UF1 and UF3. This correlates to greater stress on SubA/UF1 and SubA/UF3 die and less stress on SubA/UF2 die suggested by deflection distributions in Fig. 4 .

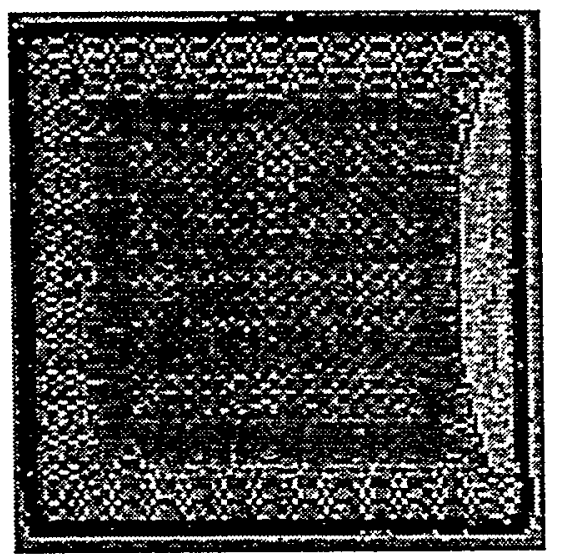

Fig. 6. C-SAM reflection image of part $S / N \quad 018$ in split Bmpl/SubA/UFl after $100 \mathrm{~T} / \mathrm{C}$ showing initial detection of die cracking.

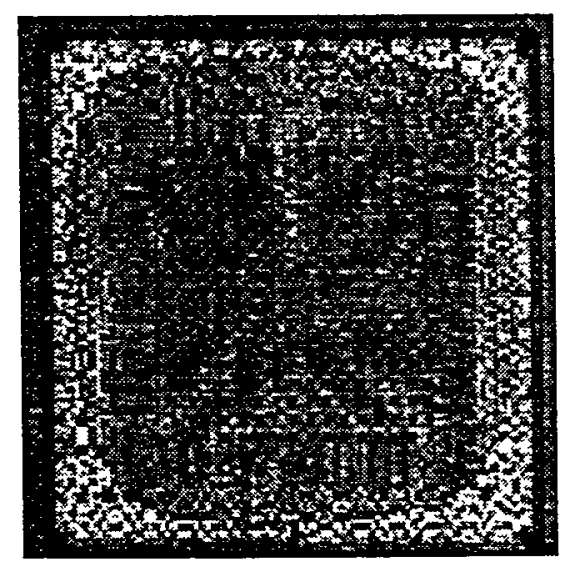

Fig. 7. C-SAM reflection image of part $\mathrm{S} / \mathrm{N} 032$ in split Bmp1/SubA/UF2 after $200 \mathrm{~T} / \mathrm{C}$ showing delamination of the underfill to die surface interface. All parts in this leg showed similar delaminations.

Significant edge delamination occurred in all 9 parts in the Bmp1/SubA/UF2 split. Fig. 7 contains a C-SAM image of one part in this group taken at the $200 \mathrm{~T} / \mathrm{C}$ off-line testing interval. A low voltage SEM inspection of this part showed debonding of the edge fillet around the entire perimeter. (See Fig. 8) It is assumed that the remaining parts in this split contain similar 
debonding. The Bmp1/SubB/UF2 split, which is identical to this split in every way except for substrate, exhibits minor edge delamination in 2 of 9 parts. The Bmp2/SubA/UF2 split, which is identical except for the solder bump supplier (die are from another wafer lot), also shows minor edge delamination in 2 of 4 parts.

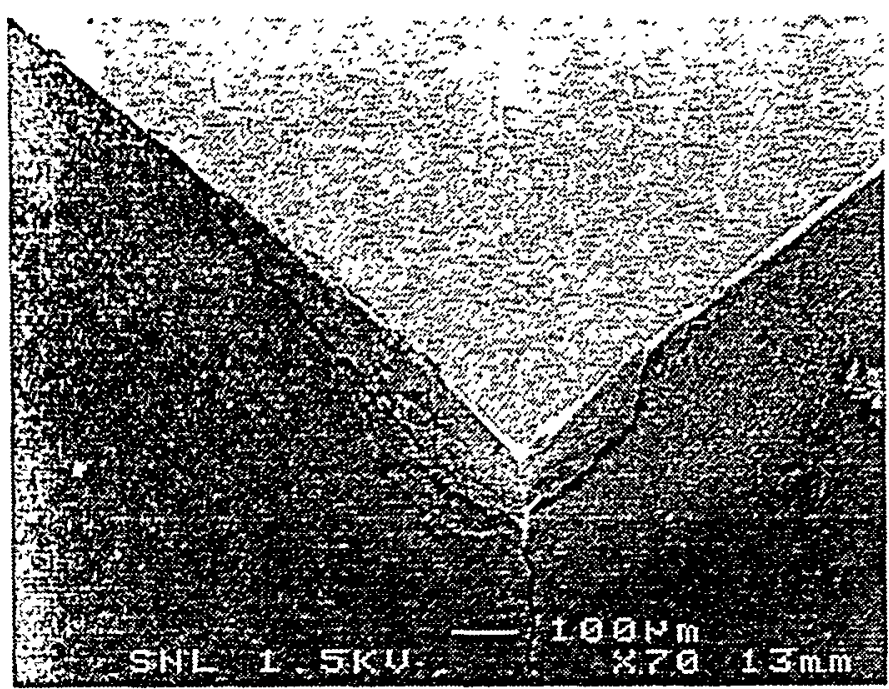

Fig. 8. SEM micrograph of S/N 032 from Bmpl/SubA/UF2 split after $200 \mathrm{~T} / \mathrm{Cs}$ showing debonding and radial cracking of the edge fillet typical of parts in this group. Debonded region is continuous around the die perimeter.

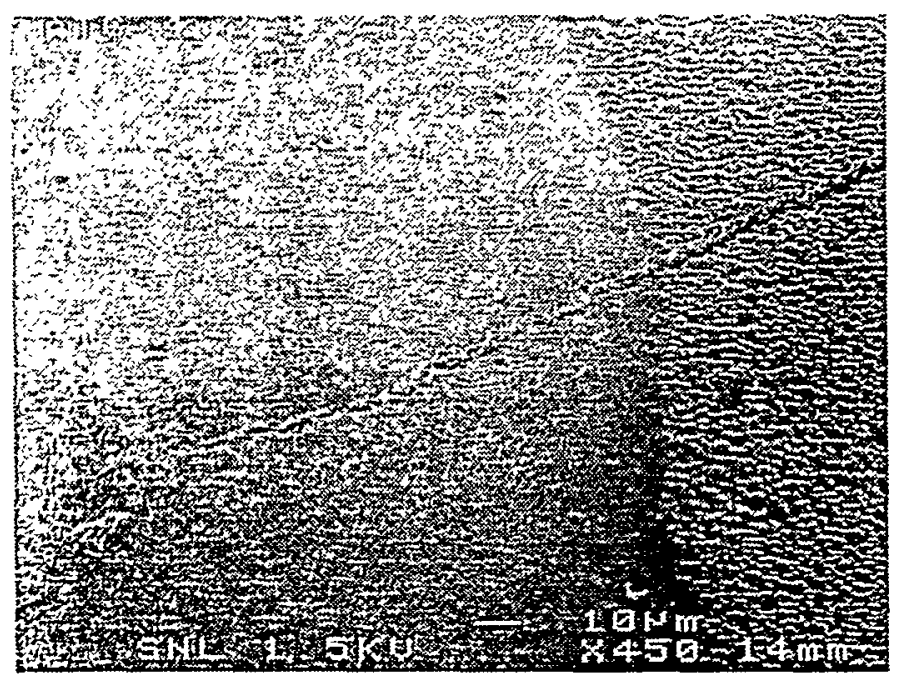

Fig. 9. SEM micrograph of $S / N 032$ from Bmpl/SubA/UF2 split after $200 \mathrm{~T} / \mathrm{Cs}$ showing continuation of the radial crack shown in Fig. 8 from the edge fillet on the right into the solder mask and possibly the build-up dielectric on the left.

The third early damage mechanism observed is radial crack propagation from die corners through the underfill edge fillet and into the substrate. This was evident in every corner of every part in the SubA groups during the course of temperature cycling. The SEM micrograph in Fig. 9 shows the radial crack in Fig. 8 proceeding into the solder mask covering the top build-up layer of the substrate. These cracks are selflimiting in length as they move away from the die footprint region but may extend into one or more layers of the build-up dielectric. Due to the small sample size in the experimental splits, we do not plan on cross-sectioning these parts to confirm crack depths until the completion of temperature cycling. The SubB groups exhibit minor cracks in only a few corners scattered across the UF2 and UF3 splits and none in the SubB/UF1 split after 500 T/Cs.

\section{Edge Fillet Damage Theory}

The out-of-plane shear stress component $\tau z y$ is very small except near the flip chip edges where it increases exponentially. This component is responsible for cyclic shear strain induced fatigue failures of solder balls around the periphery of the die. We would expect the edge fillet to reduce the magnitude of this stress, however, this is not confirmed by FEM results. The distribution of $\tau z y$ along the normalized centerline half-length of the die surface plotted in Fig. 10 does not indicate a significant difference in shape with and without the edge fillet.

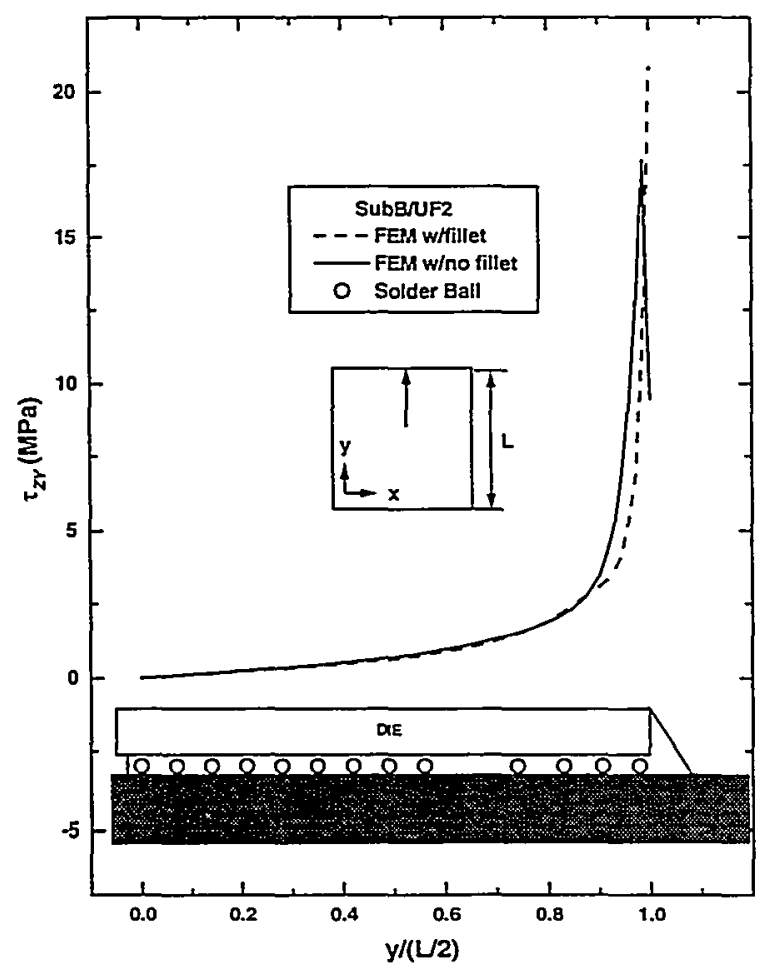

Fig. 10.Plot of $\tau z y$ distribution (shear stress on the $z$-plane in the $y$ direction) along the normalized centerline half-length of the die surface. Dashed line is FEM calculation for SubB/UF2 with edge fillet effects, solid line is case without edge fillet. Location of solder balls relative to stress distribution are shown for reference.

The edge fillet significantly affects the peel stress component $\sigma z z$. According to FEM simulations, this stress is tensile at the die perimeter without an edge fillet and highly compressive with an edge fillet. This is evident in Table VI and can be seen graphically in Fig. 11 where the distribution of $\sigma z z$ analytical and FEM calculations with and without fillet are plotted. (The no-fillet FEM simulation had numerical oscillations close to the edge, so we added a most likely 
trajectory to the plot.) The no-fillet case results in tensile conditions at the edge while the presence of the fillet tends to "squeeze" the edge of die into the substrate due to the CTE mismatch between it and the Si die.

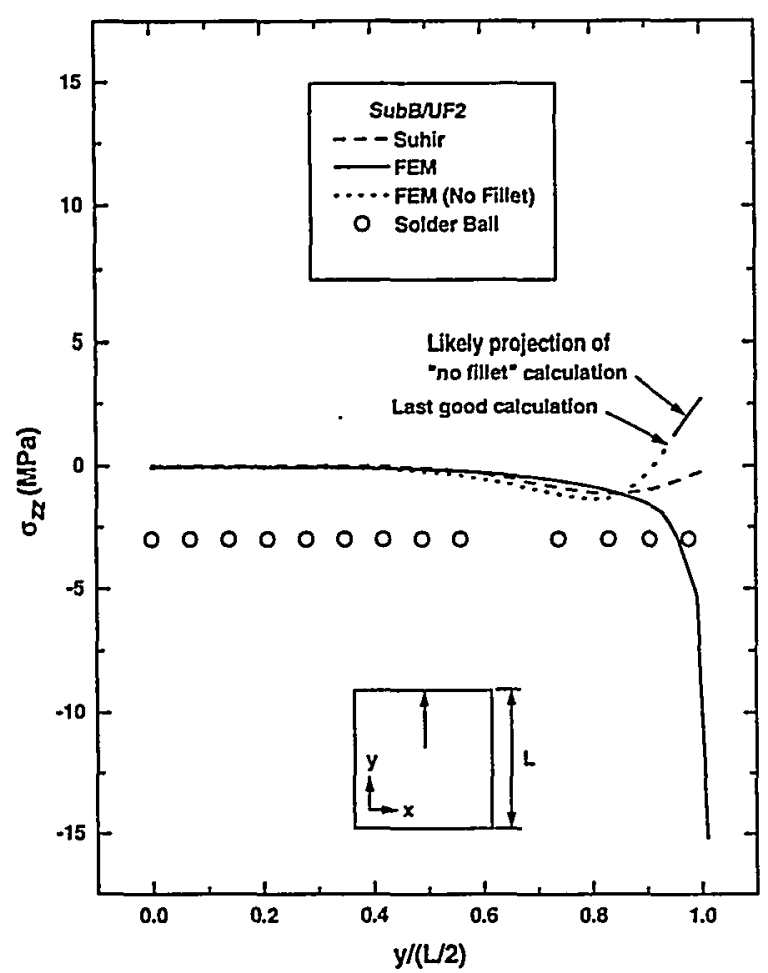

Fig. 11.Plot of $\sigma z z$ peel stress distribution along the normalized centerline half-length of the die surface. Dotted line is from Suhir (neglects edge fillet effects), dashed line is FEM with edge fillet, and dash-dot line is FEM with no edge fillet. Solder ball locations are shown for reference.

Edge delaminations observed in the Bmp1/SubA/UF2 split are attributed to complete debonding of the fillet-to-die edge interface. We speculate, lacking supporting evidence from simulations that are still in process, that a partial debond of the edge fillet will create a tensile stress riser along the die edge. Fig. 12 contains FEM calculations of the shear stress distribution on the die edge ( $y$-plane) in the $z$ direction along the normalized height of the edge for the die center and die corner. Curiously, this component shows little variation from UF2 $\rightarrow$ UF3 even though the peel stress $\sigma z z$ in the same location varies by over $86 \%$ (Table VI). The distribution in Fig. 12 shows a large negative stress at the top and positive at the bottom suggesting that the die edge is under compression by the fillet. A partial debond starting at the top would cause the peak negative (downward) stress to move along with the debond tip. The unbonded part of the edge would respond to the tendency of the die to straighten resulting in a large tensile stress concentration at the debond tip. This could lead to die cracking during temperature cycles if coincident with other risk factors such as wafer saw damage and high general die stress due to non-ideal underfill and substrate properties.

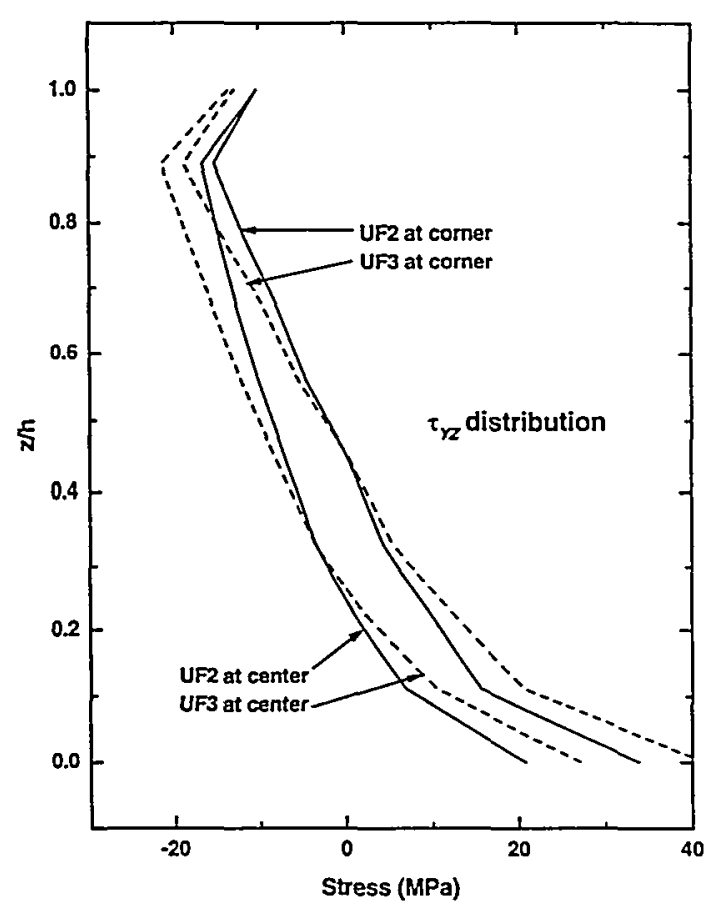

Fig. 12. Distribution of shear stress in the $y$-plane in the $z$-direction along the normalized edge of the die from SubBUF2 and SubBUF3 FEM calculations.

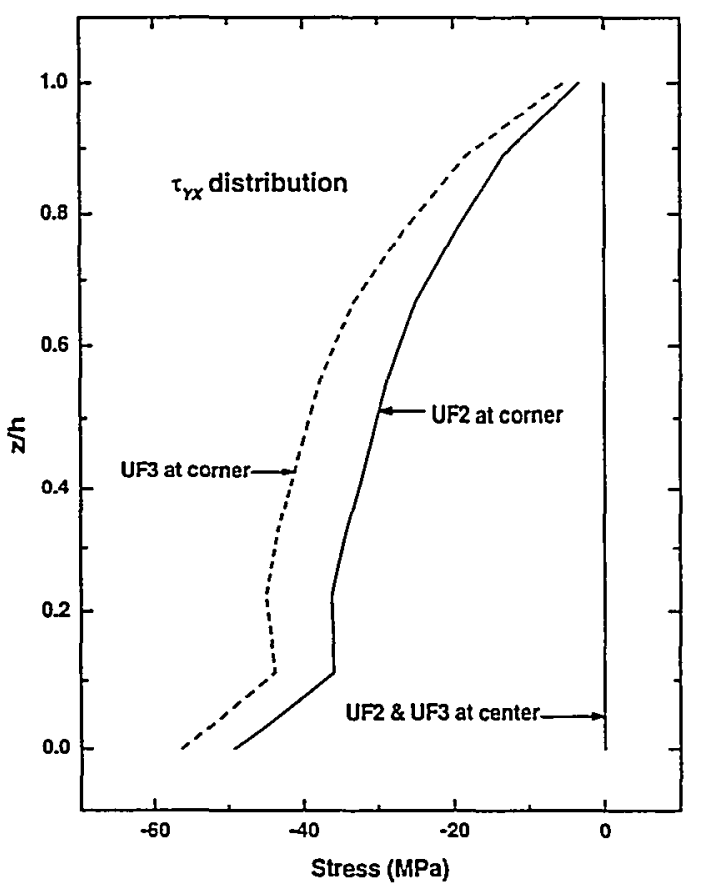

Fig. 13. Distribution of shear stress in the $y$-plane in the $x$-direction along the normalized edge of the die from SubBUF2 and SubBUF3 FEM calculations.

Radial cracking, the third damage mechanism observed, can be explained by examining in-plane stresses within the edge fillet. The fillet is under tension similar to a rubber band stretched around a box. FEM simulations show when it is properly bonded to the die edge, the tensile stress is relatively 
uniform around the perimeter, peaking slightly at die centerlines. Shear stress between the fillet and die edge are zero at the centerlines and maximum at the corners. (See Fig. 13.) Debonding would be expected to start at the highest shear region in the corner resulting in a build up of tensile stress that increases with increasing debonded area. The resulting tensile stress concentration at the corner is relieved by radial cracking.

\section{Conclusions}

Partial and complete debonding of the fillet-to-die edge interface were observed in flip chip BGA parts that exhibited die cracking and underfill-to-die interfacial edge delamination during temperature cycling. Die cracking is more likely in assemblies under greater stress and in combination with rough or dicing-saw damaged edges, but appears to be triggered by stress risers at the tip of a partially debonded edge fillet. Edge delamination, on the other hand, requires complete debonding of the edge fillet in order to initiate.

Cracks emanating from die corners through the edge fillet and proceeding radially into and along the surface of the solder mask and build-up dielectric were associated with the same debonding of the fillet-to-die edge interface. FEM simulations show relatively uniform tensile stresses in the edge fillet when bonded that become concentrated at the die corner after debonding.

The critical role of the edge fillet in preventing delamination within the underfill region raises questions about the reliability of fillet-less wafer level processes currently under development.

Analytical calculations are very useful for estimating much of the response of an FCOB assembly to thermal stress but can be misleading near the die edge due to the effect of the edge fillet.

3D FEM simulation is still the only practical way of gaining insight into the behavior of a complex assembly such as FCOB under thermal stress. This technique leads naturally to material and process optimization of the underfill and edge fillet.

\section{Acknowledgments}

The authors wish to thank the SEMATECH BGA Substrate and Underfill Interfacial Integrity Enhancement (UIIE) PTAB member company representatives along with Celestica, Zuken-Redac, ITRI, and the unnamed suppliers of materials-for their ongoing and extensive support of this work.

\section{References}

[1] D. W. Peterson, J. N. Sweet, S. N. Burchett, A. Hsia, "Stresses From Flip Chip Assembly and Underfill; Measurements with the ATC4.1 Assembly Test Chip and Analysis by Finite Element Method," Proc. $47^{\text {th }}$ Elec. Comp. \& Tech. Conf., IEEE, 1997, pp. 134-143.

[2] J. N. Sweet, D. W. Peterson, M. R. Tuck, and J. M. Greene, Assembly Test Chip Ver. 04 (ATC04)
Description and User's Guide, Sandia National Laboratories Report, SAND93-1901.

[3] N. M. Gasparini and B. K. Bhattacharyya, "A Method of Designing a Group of Bumps for C4 Packages to Maximize the Number of Bumps and Minimize the Number of Package Layers," in Proc. $44^{\text {th }}$ Elec. Comp. \& Tech. Conf., IEEE, 1995, pp. 695-699.

[4] E. Suhir, "Die Attachment Design and Its Influence on Thermal Stresses," in Proc. $37^{\text {th }}$ Elec. Comp. Conf.. IEEE, 1987, pp. 508-517.

[5] V. Mishkevich, E. Suhir, "Simplified Engineering Approach for the Evaluation of Thermally Induced Stresses in Bi-Material Microelectronic Structures," in E. Suhir, ed., Structural Analysis in Microelectronics and Fiber Optics, ASME Press, 1993, pp. 127-133. 